\section{All aboard for Halley}

The planned Soviet-French joint mission to Halley's comet in 1986 has been transferred, on the initiative of the Soviet Union, to the joint Comecon "Interkosmos"' programme. At the same time, French participation will be largely reduced to the first stage of the mission, the fly-by of Venus.

The Halley probe is now to carry apparatus from Comecon countries, although their participation seems to be confined to the provision of equipment rather than the design of any individual experiments. Some countries may be assigned an individual responsibility for various sections of the mission Hungary, for example, has been entrusted with developing the television system for monitoring the comet and transmitting the pictures to Earth.

The announcement of the Interkosmos trip to Halley's comet came at last month's meeting in Erevan of the Comecon permanent working group on space physics, only a few days after the successful landing of the Romanian cosmonaut, Dumitru Prunariu, brought to an end the programme of Comecon participation in missions to the Salyut space stations. Academician V.A. Kotel'nikov, chairman of Interkosmos, confirmed that no further joint manned flighs have been planned, although several unmanned joint missions are scheduled.

Vera Rich

tracking satellite would be able to cover the shuttle only in about half of its orbit and one third of Spacelab data could be lost. Extra recording equipment would be carried on board, but it is unlikely that the very high rate of data (100-150 megabits per second) from the microwave facility for Earth observations could be recorded. Spacelab users and ESA await NASA's final decision.

Meanwhile, NASA has been revising its schedule for shuttle flights up to 1985. Surprisingly, after the almost complete success of the first shuttle flight, delays are in store. Seven of the 44 flights scheduled before 1985 are to be postponed until the second half of the decade or even cancelled. Most other payloads are to be delayed. The reason for the delays, ranging from a few days to more than a year, are cuts in the Reagan budget, a more accurate estimate of the turn-round time and, most recently, delays in the manufacture of lightweight external fuel tanks. NASA says that delay in delivery of the tanks is largely responsible for the postponement of seven flights beyond 1985 .

Three of the seven flights will effectively be cancelled. One will be saved by launching the two Galileo probes to Jupiter, more than 400 days later than originally planned, on a single shuttle flight. Another has been saved by the cancellation of the Venus-orbiting probe.
And the third may be saved from the International Solar-Polar Mission if NASA fails to win approval for even a modified solarpolar spacecraft. (The ESA solar-polar spacecraft is included in the shuttle manifesto but with a launch date of May 1986 , more than a year later than originally planned.)

Foreign and commercial users affected by the latest shuttle delays are being given until the end of this month to decide whether they would like to use Thor Delta launchers instead.

Judy Redfearn

\section{European innovation}

\section{Brokers in demand}

\section{Luxembourg}

The role of the European Commission in creating the right environment for innovation came up again at a symposium - sponsored by the Commission - in Luxembourg last week. The three-day conference was inspired by the resolution of EEC science ministers at the end of 1979 and follows on from a similar symposium on banking and innovation held last year.

Despite the ritual homage paid to the idea that small business will make good the job losses in large companies and industries, this year's symposium highlighted the gap between the researcher and the businessman. Participants repeatedly affirmed that basic and pure research in Europe too often fail to lead to commercial application.

The implication is that the dynamism of the small American business is not so easily copied in Europe. Not only is there a lack of venture capital but linguistic differences, the small size of national markets and technical barriers are further deterrents. In addition, the sheer mass and variety of the channels through which research results are made available bewilder rather than inspire industry. So this symposium edged round to the conclusion that what is required is a broker or intermediary who could select exploitable research and help to develop it commercially.

Some effective middlemen exist. In the United Kingdom, the National Research Development Corporation was set up in 1946. The Netherlands has the Eindhoven University of Technology, which has helped 200 small and medium-sized businesses in its first year of operation. In Austria the Innovationsgesellschaft is a venture bank specializing in helping inventors to launch new products. Belgium has several industrial research parks at the Catholic University of Louvain-La-Neuve and Vrije Universiteit Brussels.

The consensus of opinion at the symposium, however, was that these innovations are inadequate. One suggestion was for a European Technology Transfer Centre, another for a European Investment Bank specializing in research. Others proposed more bulletins on the lines of the French Lettre des Sciences et Techniques which selects and condenses reports of new discoveries. Many participants argued that the mentality of scientists in the field needs changing. They should publish information less for their peers than for the end user. Or they should themselves become entrepreneurs. The Commission will now consider how best to create the environment for the scientist/entrepreneur and for a European context for the scientific information broker.

Coincidentally, the European Commission's proposals for EEC programmes in the field of new technologies microelectronics and telematics - are to be reexamined with greater interest, said $\mathrm{Mr}$ James Prior, the UK Secretary of State for Employment, after an unprecedented gathering of the EEC's finance and employment ministers in Luxembourg on 11 June with the aim of finding a solution to the growing unemployment problem. Sir Geoffrey Howe, the British Chancellor of the Exchequer, has also stated that the Commission is to bring forward new proposals to stimulate the expansion of small and medium-sized businesses.

If $\mathrm{Mr}$ Prior's words at the "Jumbo Council" are to be taken seriously, the Commission's work in the area of scientific communication is likely to be given a shot in the arm. The ministers agreed that there must be a greater coordination of the EEC's approach to new technologies.

Jasper Becker

\section{Soviet scientists}

\section{Another trial}

Dr Viktor Brailovskii, the Moscow cyberneticist faces trial this week on a charge of "disseminating fabrications ... which defame the Soviet political and social system". Dr Brailovskii has refused a defence counsel, maintaining that nothing in his conduct over the past few years needs to be defended in court.

Dr Brailovskii was dismissed from his lectureship at the Moscow Radiotechnical Institute in 1972 when he applied, with his wife and son, to emigrate to Israel. In 1973, he and his wife Irina joined the "Sunday seminar on Collective Phenomena" organized by their friends, Dr Aleksandr Voronel', for "refusnik" scientists who wished to keep up some sort of intellectual life during the waiting period between applying for a visa (and subsequently losing their jobs) and actually being allowed to emigrate. From then on they were both frequently subjected to police harassment, which intensified when $\mathrm{Dr}$ Brailovskii became organizer of the seminar following the departure of Voronel' and his successor Dr Mark Azbel' to Israel.

In 1976, Dr Brailovskii was given permission to emigrate but his wife was refused on the grounds that she had access to secret information. (Her former 